\title{
SIMBOL-SIMBOL PESAN PERSUASIF MELALUI DESIGN POSTER EVENT MUSIK NGAYOGJAZZ FESTIVAL
}

\author{
PERSUASIVE SYMBOLS THROUGH THE POSTER'S DESIGN OF NGAYOGJAZZ \\ MUSIC FESTIVAL
}

Muhammad Febry Ramadhon ${ }^{1}$, Ahmad Rudy Fardiyan²

\begin{abstract}
ABSTRAK
Poster merupakan bentuk media komunikasi yang menggunakan daya tarik visual untuk memperkenalkan, menginformasikan dan mempersuasi khalayak. Penggunaan simbol-simbol yang tepat sangat menentukan keberhasilan poster dalam menjalankan tugasnya. Penelitian ini bertujuan untuk mengetahui apa dan bagaimana simbol-simbol persuasif digunakan dalam poster Ngayogjazz Festival periode 2013-2016. Menggunakan metode Semiotika trianglemeaning dari Charles Sanders Pierce, penelitian ini merupakan penelitian kualitatif, dimana data dikumpulkan melalui dokumentasi dan studi pustaka. Hasil penelitian menunjukkan bahwa pemilihan simbol persuasif dalam desain poster Ngayogjazz Festival tidak sekedar mempertimbangkan nilai estetis desain grafis namun juga memperhatikan aspek sosiokultural target audiens di sekitar tempat penyelenggaraan event, yaitu menggabungkan makna budaya tinggi yang melekat pada musik Jazz dengan budaya tradisional milik masyarakat lokal.
\end{abstract}

Kata kunci : Simbol pesan persuasif, Semiotika Charles S Pierce, Poster .

\begin{abstract}
Poster is a media which using a visual appeal to introduce, to inform, and to persuade their audiens. The right symbols used in a poster determined the success of the poster to achieve it goals. The purpose of this research is to find out what and how persuasive symbols used by Ngayogjazz Music Festival poster on 2013-2016 period. Using a triangle meaning semiotics method by Charles Sanders Pierce, this research was a qualitative type research, where the data collected through documentation and literature. The results of this research show that the aesthetics part is not the only thing considered in the visual design of the poster. The most important thing is the collaboration's meaning of high culture on jazz music with the traditional culture of locals.
\end{abstract}

Keywords: Persuasive symbol, Semiotic of Charles S. Pearce, Poster

\section{PENDAHULUAN}

Poster merupakan salah satu bentuk media cetak visual yang memiliki sistem penandaan dan sintaks. Dalam sistem semiotika visual melekat fungsi komunikasi, yaitu fungsi tanda dalam menyampaikan pesan dari pengirim pesan kepada penerima

\footnotetext{
1 Jurusan Ilmu Komunikasi Universitas Lampung, 991.one@gmail.com

2 Jurusan IImu Komunikasi Universitas Lampung ; ahmad.rudy@fisip.unila.ac.id
} 
berdasarkan aturan atau kode-kode tertentu. Meskipun fungsi komunikasi menjadi fungsi utamanya, bentuk-bentuk komunikasi visual juga mempunyai fungsi signifikasi, yaitu fungsi dalam menyampaikan sebuah konsep isi, atau makna. (Tinarbuko, 2008:21). Tujuan dari desain komunikasi visual adalah untuk menyampaikan pesan, mendapatkan perhatian (atensi) dari mata (secara visual) dan membuat pesan tersebut dapat diingat dalam hal ini poster. Dalam dunia periklanan suatu barang atau jasa tentu proses penyampaiannya menggunakan persuasive appeals atau melalui pendeketan persuasif. Komunikasi persuasif itu sendiri dapat diartikan sebagai sebuah pendekatan komunikasi untuk dapat meyakinkan dan membujuk komunikan dengan sebuah argumen yang menguraikan suatu masalah atau keadaan yang dibuktikan dengan data dan fakta yang bertujuan untuk memengaruhi agar persuadee atau komunikan dapat mengikuti apa yang diharapkan komunikator.

Seiring dengan perkembangan zaman ini, poster banyak digunakan didalam bidang hiburan terutama dalam dunia hiburan panggung musik atau even musik. Salah satu event musik di Indonesia yang cukup diperhitungkan adalah Ngayogjazz Festival yang diselenggarakan setiap tahun pada setiap bulan November sejak tahun 2007 hingga sekarang di Yogyakarta. Festival musik jazz "Ngayogjazz” bermakna Ngayogjakarto Jazz atau Jazz Yogyakarta. Ngayogjazz ini tidak hanya menarik perhatian orang-orang yang tinggal di Yogyakarta ataupun Indonesia, tetapi juga yang berasal dari luar Indonesia. Bagi para pengunjung, pengalaman yang mereka temukan di Ngayogjazz telah memberikan warna tersendiri. Berangkat dari keinginan untuk menghapus citra musik jazz yang elitis, Djaduk Ferianto, penggagas Ngayogjazz berkeyakinan bahwa jazz sebagai musik yang terbuka dan luwes bisa diapresiasi semua lapisan masyarakat dan dapat berbaur dengan kehidupan budaya setempat. Bekerjasama dengan WartaJazz serta rekan musisi lainnya, akhirnya Djaduk Ferianto sepakat melahirkan gagasan acara jazz festival dengan diberi nama Ngayogjazz ${ }^{3}$

Mengemban misi untuk membumikan musik jazz di kalangan masyarakat jawa, pelaksana Ngayogjazz memerlukan bentuk media promosi yang tepat dengan tema yang sesuai dengan visi dan misi kegiatan tersebut. Salah satu media yang digunakan untuk memperkenalkan dan mempromosikan Ngayogjazz adalah poster. Poster sendiri

\footnotetext{
${ }^{3}$ http://www.wartajazz.com/opini-jazz/2011/01/12/ngayogjazz-dan-momentum-perubahan. (diakses pada 5 februari 2017, pkl 20.00 WIB)
}

24 | Simbol-Simbol Pesan Persuasif Melalui Design Poster Event Musik Ngayogjazz Festival 
merupakan bentuk media publikasi yang terdiri atas tulisan, gambar ataupun kombinasi antar keduanya dengan tujuan memberikan informasi kepada khalayak ramai. Poster dalam pengertiannya adalah gambar pada selembar kertas berukuran besar yang digantung atau ditempel di dinding atau permukaan lain sebagai alat untuk mengiklankan sesuatu, sebagai alat propaganda, protes, serta maksud-maksud lain untuk menyampaikan berbagai pesan. (Kusrianto, 2007:338). Informasi yang ada pada poster tentunya bersifat mengajak atau mempersuasif masyarakat dengan menggunakan bermacam-macam simbol dan ilustrasi yang menggambarkan acara tersebut. Tema yang dimasukan dalam tiap posternya pun beragam mengikuti trend zaman dan mengikuti jenis musik apa yang akan ditampilkan dalam penelitian ini adalah musik Jazz, dengan memperhatikan design visualnya

Gambaran poster sebagai media informasi dan mempersuasif masyarakat dapat kita lihat pada poster even musik Ngayogjazz Festival. Dalam hal ini, poster yang diteliti adalah empat poster dari even Ngayogjazz festival periode 2013-2016. Pada setiap posternya menampilkan ilustrasi seni adat jawa seperti pemain kuda lumping, burung garuda, pewayangan yang semuanya disandingkankan dengan ilustrasi alat musik khas musik jazz. Ilustrasi yang seperti ini dinilai menarik karena berhasil membuat rasa penasaran akan bagaimana acara musik jazz yang akan diselenggarakan bagi khalayak yang melihatnya terutama bagi penikmat musik jazz itu sendiri ataupun khalayak yang sudah pernah hadir dalam even musik tersebut. Ini terbukti dari banyaknya respon, komentar dari masyarakat dan media dalam portal online seperti blog ataupun website berita online terhadap segala bentuk konsep acara Ngayogjazz Festival termasuk posternya (log.viva.co.id/fream/read) ${ }^{4}$. Berdasarkan hal tersebut, secara tidak langsung menyatakan bahwa Ngayogjazz festival bukan hanya berhasil menyampaikan informasi dan mempersuasif khalayak untuk hadir, tetapi juga berhasil menyampaikan komunikasi yang tepat dalam design poster dalam usaha meyelenggarakan sebuah even. Poster-poster ini seolah berhasil memicu rasa penasaran khalayak tentang apa dan bagaimana konsep Ngayogjazz akan diselenggarakan, simbol tanda dan ilustrasi yang disuguhkan dalam desain poster berhasil mempersuasif khalayak untuk hadir dalam Ngayogjazz festival.

\footnotetext{
${ }^{4}$ Berita Ngayogjazz festival. http://log.viva.co.id/frame/read/aHR0cDovL3Npc2loaWR1cGt1LndvcmRwcmVzcy5jb20vMjAxNC8xMS8yNi9uZ 2F5b2dqYXp6LWJ1a2FuLWhhbnlhLXN1Z3VoYW4tamF6ei8. diakses 23 April 2017, 20.00 WIB
} 
Poster sebagai karya desain komunikasi visual, memiliki sistem semiotika khusus dengan perbendaharaan tanda dan sintaks. Dalam hal ini sistem semiotika visual melekat fungsi komunikasi, yaitu fungsi tanda dalam menyampaikan pesan dari pengirim pesan kepada penerima berdasarkan aturan atau kodekode tertentu. Meskipun fungsi komunikasi menjadi fungsi utamanya, bentuk-bentuk komunikasi visual juga mempunyai fungsi signifikasi, yaitu fungsi dalam menyampaikan sebuah konsep, isi, atau makna. Hal ini membuat peneliti penasaran apa sajakah simbol-simbol persuasif didalam desain posternya dan bagaimana simbol persuasif tersebut di representasikan dalam desain poster Ngayogjazz festival pada periode 2013-2016.

Penelitian ini difokuskan pada poster event sebagai media komunikasi visual yang menampilkan seni dan pesan/makna informasi yang persuasif kepada masyarakat berdasarkan desain visual poster meliput warna, tipografi, dan ilustrasi dengan melakukan analisis tanda dan simbol yang terdapat dalam design poster menggunakan analisis semiotika Charles S. Pierce untuk mengartikan berdasarkan objeknya dan mendapatkan sebuah pemaknaan/ interpretasi simbol persuasif dari simbol - simbol pada design poster Ngayogjazz Festival.

Penelitian ini dilakukan untuk mengetahui apa dan bagaimana simbol-simbol persuasif direpresentasikan melalui desain visual poster meliput warna, tipografi, dan ilustrasi dalam poster musik Ngayogjazz Festival periode 2013-2016.

\section{METODE PENELITIAN}

Penelitian ini menggunakan metode analisis teks kualitatif dengan pendekatan semiotika segi tiga makna oleh Charles S Pierce. Penelitian kualitatif digunakan untuk mengetahui dan menganalisa apa yang justru tidak terlihat, atau dengan kata lain ingin melihat isi komunikasi yang tersirat. Fokus pada penelitian ini adalah mengetahui apa saja dan bagaimana simbol pesan persuasif direpresentasikan melalui tanda, simbol, dalam design poster event Ngayogjazz Festival. Sumber data dalam penelitian ini adalah berupa empat poster event Ngayogjazz Festival sebanyak empat buah, yang telah dipilih berdasar visual poster nya menggunakan desian grafis. Teknik penumpulan data pada penelitian ini melalui dokumentasi dan studi pustaka. 


\section{HASIL DAN PEMBAHASAN}

\section{A. HASIL}

Setiap representamen pada poster 1, 2, 3, dan 4 Ngayogjazz memberikan sentuhan atau unsur persuasi untuk datang ke pagelaran musik tersebut melalui penggambaran ilustrasi, penentuan tipografi dan pemilihan warna ilustrasi. Berikut simbol persuasi yang terkandung dalam keempat poster tersebut :

Pesan persuasi poster 1, 2, 3, dan 4 saling berkaitan karena isi ilustrasinya merupakan gambaran keseluruhan ataupun petunjuk yang mendeskripsikan kegembiraan dalam menonton event Ngayogjazz, yaitu menyatakan pagelaran musik jazz yang dikemas dengan ilustrasi perpaduan unsur modern dan unsur tradisional yang kesemuanya ada di dalam keempat poster diatas. Hal ini dimaksudkan untuk meleburkan image budaya tinggi pada musik Jazz dan membumikan Jazz itu sendiri kepada masyarakat untuk lebih luas dan lebih menyentuh masyarakat bawah.

Tipografi keempat poster menggunakan desain dan pemilihan font yang tepat untuk menggambarkan dengan jelas event apa yang akan berlangsung, pengisi acara yang mengisi event tersebut, dan juga waktu serta lokasi event tersebut diselenggarakan. Dengan adanya pemilihan jenis huruf atau font yang tepat akan dapat menghasilkan kesan yang sesuai dengan karakteristik poster dan pesan yang diinginkan komunikator untuk mempengaruhi secara konatif untuk membaca ataupun melihat poster.

Keempat poster yang ada masing-masing juga menjadi menarik dengan pemilihan tagline tema acara yang unik dan berkesan dimata orang yang melihatnya, sehingga membuat orang-orang ingin datang setelah melihat keempat poster diatas. Kata Unik disini digambarkan oleh penggunaan bahasa daerah Jawa dalam menuliskan tagline nya dimana tagline yang digunakan juga mempunyai arti makna yang filosofis ciri khas lokal Indonesia. Hal tersebut jelas menandakan sebuah sajian kolaborasi dari unsur modern luar dan unsur lokal khususnnya Indonesia yang mempengarui secara dan kognisi dari pembaca.

Pemilihan warna keempat poster yang hampir semuanya berbeda-beda setiap eventnya menunjukkan kreativitas dari penyelenggara itu sendiri. Dengan pemilihan warna yang berbeda, kita dapat membedakan tema event Ngayogjazz yang berbeda setiap tahunnya, tergantung pemilihan warna yang dipilih oelh penyelenggara event ini. Dalam 
pemilihan warna poster-poster diatas memperhatikan fungsi warna didalam sebuah poster atau seni grafis, dalam poster nya Ngayogjazz selain mementingkan sebuah keindahan visual dan keharmonisan warna, penggunaan warna terang akan lebih cepat menarik perhatian walaupun pada jarak penglihatan yang relatif cukup jauh, karena warna terang akan memantulkan cahya lebih jauh dari pada warna gelap. Sedangkan penggunaan kombinasi dari warna-warna gelap dapat digunakan dengan tujuan menarik perhatian dari jarak dekat, tentu dengan tujuan-tujuan khusus dari perancang poster. Pemilihan warna dalam tipografi juga penting karena warna yang mudah terbaca pada penggunaan tipografi akan membawa efek pada yang memandang, sehingga pada akhirnya warna akan berdampak mencegah adanya kesalahan dalam membaca dan menekankan pesan pesan yang penting didalamnya. Hal ini juga dapat mempengaruhi kognisi dari pembaca dalam menerima pesan yang dalam hal ini adalah pesan persuasifnya.

\section{B. PEMBAHASAN}

Berdasarkan hasil analisis poster Ngayogjazz 2013 - 2016, terdapat banyak sekali unsur budaya atau adat istiadat setempat yang menjadi simbol atau pesan untuk mengajak orang-orang yang ada di sekitar untuk datang dan menyaksikan pertunjukan musik Ngayogjazz tersebut. Unsur ajakan tersebut adalah unsur persuasi yang terdapat dalam poster Ngayogjazz.

Berbicara tentang musik Jazz, kita juga harus berbicara mengenai budaya tinggi yang merupakan budaya yang mengadopsi musik tersebut. Jazz adalah sebuah seni ekspresi dalam bentuk music, Jazz disebut sebagai musik fundamental dalam hidup manusia dan cara mengevaluasi nilai-nilai tradisionalnya. Tradisi jazz berkembang dari gaya hidup masyarakat kulit hitam di Amerika yang tertindas. Jazz memang lahir dan besar di segala tempat dalam kondisi tekanan sosial, konflik sosial dan kriminalitas tumbuh menjamur di kawasan Amerika Serikat di masa lalu seperti klub malam/bar yang menjadi arena tempat perjudian, prostitusi, transaksi narkotika dan segala stereotip negatif yang melekat terhadapnya. ${ }^{5}$

Titik balik dimana musik Jazz beralih menjadi budaya tinggi adalah pada tahun 1917, dimana kemunculan band jazz legenda seperti "King Oliver and Creole Jazz

\footnotetext{
${ }^{5}$ (http://riefmusiclife.co.id/2014/10/sejarah-musik-jazz), diakses pada 10 Oktober 2017, pukul 17.00.)

28 | Simbol-Simbol Pesan Persuasif Melalui Design Poster Event Musik Ngayogjazz Festival
} 
Band"yang dimana pemain trompet sekaligus musisi jazz dunia yakni Louis Armstrong ikut menggawanginya dengan banyak melakukan aksi solo melalui rhytem section yang menjadi cirri khas mereka dalam beberapa pertunjukan secara live radio di Amerika Serikat.

Pada masa itulah dimulai era dimana Jazz populer bahkan juga digemari kalangan luas. Jazz yang didatangkan ke Indonesia untuk menghibur orang orang asing yang masih menduduki bumi Indonesia saat itu, tentunya dikemas dalam acara dan tempat yang elit, dan pada perkembangannya pun akhirnya musik jazz di Indonesia banyak dipentaskan di hotel, bar, cafe dan tempat-tempat sejenisnya sehingga terkesan lah Jazz bukan lagi dipandang sebagai Budaya Rendah yang melainkan sebagai Budaya Tinggi khususnya di Indonesia.

Berbicara tentang budaya tinggi, kita berbicara sebuah karya yang memiliki target audience tersendiri karena hanya beberapa orang yang memahami atau karya tersebut merupakan karya yang mahal dan tidak semua orang dapat menjangkaunya. Budaya Tinggi ialah tentang budaya yang mengagungkan nilai - nilai bersumber dari pemikiran kaum pelajar, sedangkan budaya rakyat (folk culture) lahir dari pemikiran yang luhur tradisi masyarakat terdahulu dan diturunkan secara turun-temurun. Menurut Bourdieu dalam (Yoseph, 2012), kebudayaan tinggi ialah hasil karya para elit yang muncul akibat hak istimewa yang mereka dimiliki. Menurut Sosisolog Prancis, Pierre Burdieu didalam (Amrillah, 2016) budaya-budaya seperti ini dapat terjadi pergeseran yang dipengaruhi oleh waktu dan jaman. Hal ini dpat dilihat contoh dari karya-karya Shakespheare, pada jamannya karyanya tidak lebih dari sebuah teater pop. Akan tetapi saat ini karyanya dianggap sebagai budaya tinggi karena memiliki eksklusifitas penikmat dalam setiap karyanya.

Seperti yang penulis temui setelah menganilis poster Ngayogjazz, ada kesan penyelenggara pertunjukan musik tersebut berusaha mengemasnya lekat dengan simbol-simbol sosiokultural adat setempat, yaitu adat atau budaya Jawa.

Adat Jawa melekat akan tradisi nenek moyang yang di dalamnya tercampur unsur praHindu, Hindu-Jawa, dan Islam serta animisme pada kebiasaan atau aturan-aturan budaya yang dibentuk demi kesejahteraan hidup manusia terutama adat-istiadat, sopan santun, kaidah pergaulan (etik), kesusastraan, kesenian, keindahan (estetika), mistik, 
ketuhanan, falsafah dan apapun yang termasuk unsur kebudayaan masyarakat Jawa atau Orang Jawa.

Disinilah timbul pertanyaan, apakah maksud dan keterkaitan atau hubungan ketiga unsur tersebut yang berusaha disampaikan penyelenggara Ngayogjazz lewat desain poster yang mereka rilis.

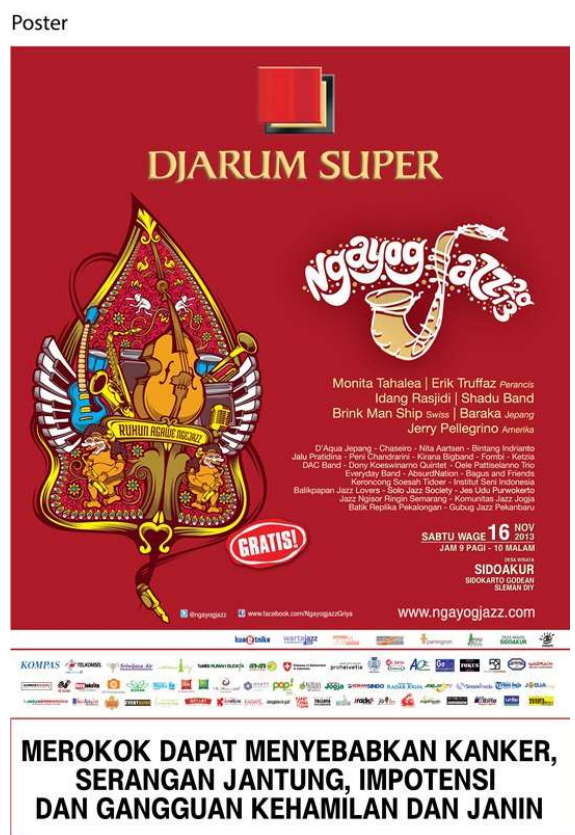

Gambar 1. Penggabungan Unsur Budaya Tinggi dan Sosiokultural Adat Jawa (Poster 2013)

Pada gambar diatas, terdapat penggunaan kedua unsur yaitu budaya tinggi yang dipadu padankan dengan unsur sosiokultural adat Jawa. Terdapat Alat musik piano yang diletakan vertikal di sisi kanan dan kiri, kemudian Alat musik contrabass, drum, saxofon, terompet \& musik serta Amplifier Instrument yang disusun sedemikian rupa sehingga membentuk satu kesatuan, tak lupa dengan sentuhan wayang yang membingkai kumpulan simbol tersebut.

Elemen semiotika visual pada gambar tersebut selain mempunyai makna dekoratif, pada ilustrasi alat musik yang disusun, dan mempertegas akan pagelaran yang dilaksanakan adalah pagelaran musik yang meyatakan genre dari musik itu, dimana genrenya merupakan Musik Jazz. Penggabungan beberapa simbol Jazz tersebut dengan wayang yang memiliki filosofi dan makna sejarahnya sendiri yang masih dianggap lekat dengan masyarakat keseniannya menurut analisis penulis tak lain dan tak bukan untuk menekankan makna ajakan atau persuasi agar masyarakat sekitar yang notabene 
merupakan masyarakat menengah atau rakyat biasa dapat terbiasa dengan atmosfer sosiokultural mereka sendiri, kedekatan masyarakat karena berkaitan dengan simbolsimbol Adat Jawa.

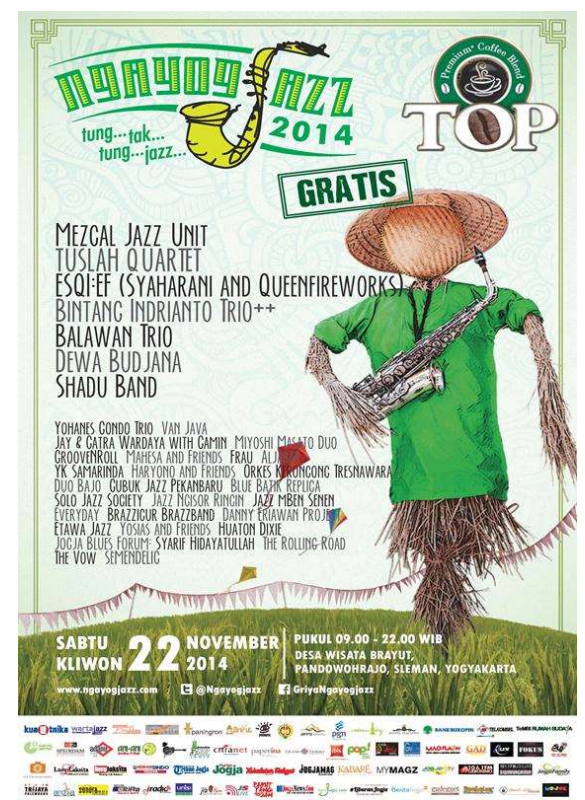

Gambar 2. Penggabungan Unsur Budaya Tinggi dan Sosiokultural Adat Jawa (Poster 2014)

Pada gambar diatas, peneliti melihat terdapat penggunaan kedua unsur yaitu budaya tinggi yang dipadu padankan dengan unsur sosiokultural budaya setempat yaitu penggambaran orang-orangan sawah yang erat kaitannya dengan tradisi masyarakat sekitar yang terbiasa bercocok tanam dan lekat pula hubungannya dengan masyarakat kelas bawah (petani/pedesaaan) dalam kesehariannya selain tujuan aslinya yang menggambarkan suasana sebenarnya dari lokasi event diadakan.

Elemen semiotika visual pada gambar diatas kembali menekankan tentang penggambaran makna dekoratif pada ilustrasi orang-orangan sawah atau memedi sawah yang menunjukkan visual merakyat dan simbol areal pesawahan terutama di desa tempat acara berlangsung. Orang-orangan sawah tersebut membawa saxophone sebagai visual yang menunjukkan bahwa acara yang dibawakan ialah acara musik jazz. Selain itu, dengan adanya ilustrasi orang-orangan sawah yang berkaitan erat dengan kebiasaan atau tradisi masyarakat setempat yang masih bercocok tanam, sehingga secara tak langsung menyampaikan pesan pada masyarakat biasa bahwa Jazz tidak hanya dapat dinikmati oleh kalangan tinggi. 


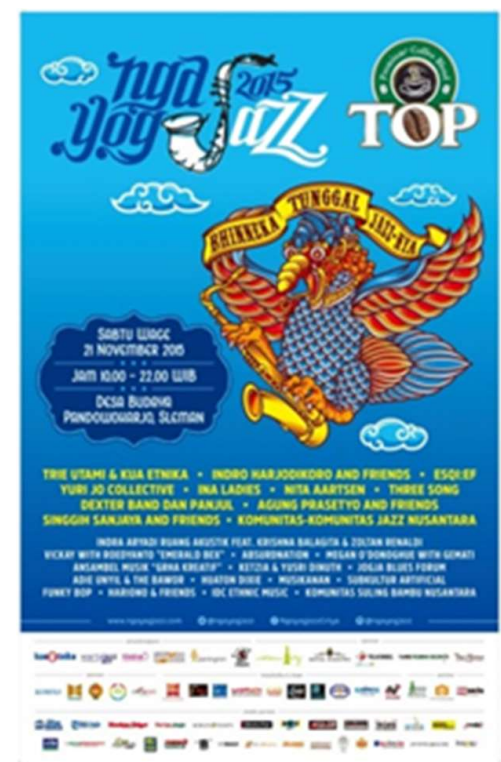

Gambar 3.. Penggabungan Unsur Budaya Tinggi dan Sosiokultural Adat Jawa (Poster 2015)

Pada gambar diatas, terlihat pula penggunaan kedua unsur yaitu budaya tinggi yang dipadu padankan dengan unsur sosiokultural budaya masyarakat Indonesia yaitu penggambaran burung Garuda yang merupakan adaptasi dari simbol Garuda pancasila berdasar penggunaan semboyan "Bhineka Tunggal Jazznya" juga adaptasi budaya jawaHindu (tokoh pewayangan) yang masih dilestarikan oleh masyarakat Jawa sampai sekarang.

Seperti yang telah penulis jabarkan sebelumnya di tinjauan pustaka Budaya Jawa bersifat sinkretis yang menyatukan unsur-unsur pra-Hindu, Hindu- Jawa, dan Islam serta animisme. Semiotika visual ilustrasi Burung Garuda yang digambarkan seperti penggambaran masyarakat Jawa yang diadopsi dari budaya Hindu terlihat mencengkeram saxofon sebagai simbol dari jazz yang merupakan produk dari budaya tinggi itu sendiri, sehingga jelas terlihat perpaduan antara aspek sosiokultural budaya setempat dengan aspek budaya tinggi.

Ilustrasi diatas menggambarkan makna dekoratif mempertegas akan pagelaran yang dilaksanakan adalah pagelaran musik Jazz yang meyatakan genre dari musik itu sendiri dan kolaborasi seni modern dan tradisional dengan segala aspek nilai morilnya. Peneliti asumsikan Burung Garuda sebagai simbol persatuan dengan mencengkram alat musik saxofone ciri khas musik jazz yang menyerukan dengan jelas bahwa dengan musik Jazz bisa menjadi wadah kita untuk menjaga kerukunan dalam keberagaman dengan cara 
bergembira mendengarkan festival musik jazz.Penggunaan istilah "Bhinneka Tunggal Jazz-nya" yang mempunyai arti jazz untuk semua kalangan juga merupakan aspek sosiokultural Indonesia yaitu berasal dari "Bhinneka Tunggal Ika" yang merupakan semboyan bansa Indonesia yang berarti Berbeda-Beda Tetapi Tetap Satu Jua. Dari ilustrasi inilah dapat penulis tarik benang merah bahwa penyelnggara Ngayaogjazz berusaha mempersuasi masyarakat dengan 'menggoda' nalar kita dengan unsur-unsur sosiokultural yang kita sendiri, bangsa Indonesia, sangant kenal dan pahami sedari kecil.

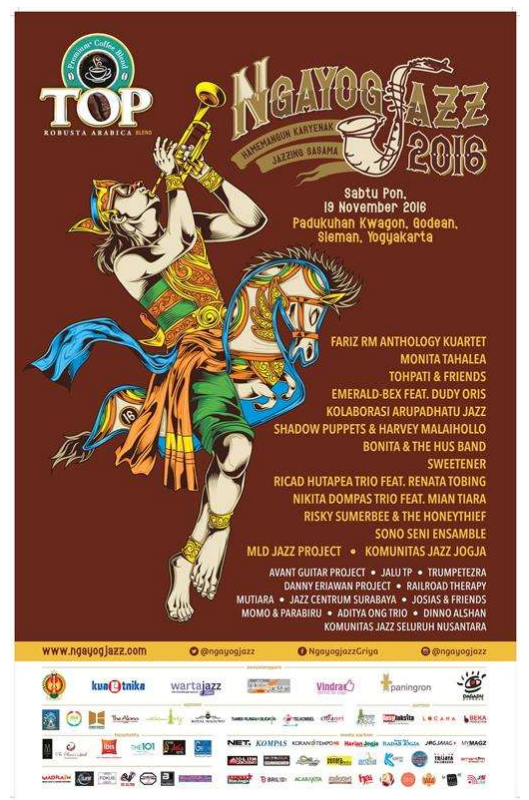

Gambar 4. Penggabungan Unsur Budaya Tinggi dan Sosiokultural Adat Jawa (Poster 2016)

Pada gambar terakhir, juga terlihat penggunaan kedua unsur yaitu budaya tinggi yang juga dipadu padankan dengan unsur sosiokultural budaya masyarakat Jawa, yaitu Wayang Orang kudang lumping atau Jathilan memakai kacamata hitam yang menari sambil memainkan alat musik khas Jazz, yaitu trumpet.

Semiotika visual ilustrasi diatas menggambarkan kolaborasi pagelaran seni Tradisonal dan modern yang dapat dinikmati semua kalangan (universal), serta tidak membedakan golongan ataupun status individu itu sendiri. Pertama, penggambaran Jathilan yang tengah menari sambil bermain alat musik merupakan unsur sosiokultural dari budaya Jawa. Wayang orang sendiri merupakan kesenian asli dari budaya atau adat Jawa yang biasanya di pertunjukan kepada hal-hal yang berbau kegembiraan/keceriaan (pesta rakyat, pesta keluarga, perayaan). 
Hal diatas menimbulkan kesan persuasi atau ajakan, dimana penyelenggara lewat poster yang mereka desain berusaha menarik khalayak atau masyarakat, khsuusnya ditempat pagelaran itu berada untuk datang dan menyaksikan pagelaran musik tersebut untuk bergembira bersama lewat paduan kolaborasi dua unsur. ilustrasi Jathilan pada poster mengisyaratkan sebuat kegembiraan dalam sebuah pesta rakyat yang dikolaborasikan dengan jazz, sehingga tergambarkan bahwa musik jazz menjadi salah satu cara atau suguhan yang menarik.

Jadi secara keseluruhan, berdasarkan apa yang telah peneliti terangkan diatas bahwa design poster Ngayogjazz 2013-2016 memiliki arti semiotikavisual yang berbeda-beda, dari analisis semiotika Charles S. Pierce yang membahas secara detail mengenai isi dari setiap simbol dalam poster yang menjadi salah satu media promosi dan mempersuasif lewat simbol-simbol didalam poster Ngayogjazz itu sendiri seperti yang telah didapatkan dlam penelitian terdahulu penelitian ini. Pemilihan atau penggunaan simbol dalam desain poster Ngayogjazz Festival tidak hanya semata memikirkan nilai estetis/dekoratif dari sebuah karya seni desain grafis. Dalam penciptaannya pemillihan sebuah simbol memperhatikan sosiokultural setempat, selain itu juga memperhatikan tujuan awal Ngayogjazz festival ini diadakan yaitu membumikan, meleburkan image Jazz sebagai budaya kelas tinggi, bahwa genre musik Jazz sebagai musik yang terbuka dan luwes bisa diapresiasi semua lapisan masyarakat dan dapat berbaur dengan kehidupan budaya setempat dan merupakan salah satu wadah untuk bergembira bersama. Dengan menggunakan tanda-tanda yang dipahami oleh masyarakat sekitar pada khususnya dan generasi muda pada umumnya, diharapkan Ngayogjazz terasa dekat dan menjadi bagian dari kegiatan bermusik dan berbudaya baik di Yogyakarta maupun secara luas di Indonesia. Sebab-sebab itulah yang menjadi tolak ukur dalam pemilihan simbol dalam pembuatan desain poster Ngayogjazz festival yang diharapkan bisa memangkas jarak musik Jazz membumikan musik Jazz dengan masyarakat dan meleburkan image bahwa musik Jazz hanya untuk kalangan tertentu yang terkesan elit, sehingga pada akhirnya mempersuasif masyarakat untuk hadir dalam event Ngayogjazz Festival. 


\section{PENUTUP}

\section{A. SIMPULAN}

Simbol-simbol pesan persuasif yang terdapat dalam design poster event Ngayogjazz festival terdapat pada beberapa visualisasi berdasarkan ilustrasi, penggunaan font, penggunaan warna dalam background maupun tipografi, pemilihan Tagline dari tema acara, dan beberapa pernyataan informasi mengenai informasi pengisi acara.

Adapun simbol persuasi direpresentasikan dalam keempat poster tersebut yaitu:

1. Ilustrasi budaya lokal yang unik dikolaborasikan dengan ilustrasi simbol musik Jazz atau unsur seni modern, terasa sebuah bentuk kolaboorasi dua budaya yang berbeda, tanpa mengubah makna filosofi dari ilustrasi budaya lokal nya dan dikolaborasikan dengan simbol Jazz menghasilkan sebuah makna gambaran positif bagi Jazz dan pagelaran Ngayogjazz itu sendiri bagi masyarakat yang masih erat dengan seni atau budaya tradisional.

2. Tipografi keempat poster menggunakan desain dan pemilihan font yang tepat untuk menggambarkan dengan jelas event apa yang akan berlangsung, pengisi acara yang mengisi event tersebut, dan juga waktu serta lokasi event tersebut diselenggarakan. Dengan adanya pemilihan jenis huruf atau font yang tepat akan dapat menghasilkan kesan yang sesuai dengan karakteristik poster dan pesan yang diinginkan komunikator.

3. Keempat poster yang ada masing-masing juga menjadi menarik dengan pemilihan tagline tema acara yang unik, Kata Unik disini digambarkan oleh penggunaan bahasa daerah Jawa dalam menuliskan tagline nya dimana tagline yang digunakan juga mempunyai arti makna yang filosofis ciri khas lokal Indonesia.

4. Dalam pemilihan warna poster-poster diatas memperhatikan fungsi warna didalam sebuah poster atau seni grafis, dalam poster nya Ngayogjazz selain mementingkan sebuah keindahan visual dan keharmonisan warna, Pemilihan warna dalam tipografi juga penting karena warna yang mudah terbaca pada penggunaan tipografi akan membawa efek pada yang memandang.

5. Dalam design-nya pemilihan atau penggunaan simbol dalam desain poster Ngayogjazz Festival tidak hanya semata memikirkan nilai estetis dari sebuah 
karya seni desain grafis. Dalam penciptaannya pemillihan sebuah simbol memperhatikan sosiokultural setempat, selain itu juga memperhatikan tujuan awal Ngayogjazz festival.

\section{B. SARAN}

Peniltian ini merupakan upaya untuk menjawab pertanyaan penelitian yang berkaitan dengan paradigma jazz dalam ranah sosial, objek pemaknaan tidak cukup hanya dimaknai secara tekstual sebagai objek seni, melainkan harus pula dimaknai secara kontekstual. Oleh karena itu, maka saran dari penelitian yang penulis susun ini adalah:

1. Untuk penelitian selanjutnya, peneliti menyarankan agar dapat menambah konteks penelitian dan semiotik symbol persuasif dari poster atau media lain, Karena pada penelitian ini hanya mencari apa sajakah simbol persuasifnya sehingga belum diketahui apakah simbol persuasif dalam poster berpengaruh kepada masyarakat yang melihatnya sebagaimana fungsi media poster yaitu sebagai media persuasif.

2. Dalam bidang akademik, harapan peneliti agar pihak akademik lebih dapat memperdalam lagi untuk bidang kajian semiotika dengan tujuan untuk dapat lebih mempertajam kemampuan mahasiswa dalam menganalisis dan mengungkap gejala atau fenomena yang terkait dengan dunia Ilmu Komunikasi, khususnya pada kajian komunikasi visual atau bidang periklanan pada media massa seperti poster.

3. Para designer poster hendaknya lebih memperhatikan sosiokultural sekitar dalam pembuatan poster khususnya poster event,dikarenakan pentingnya memperhatikan pemilihan symbol/desain demi tersampainya pesan yang ingin disampaikan ke para pembaca.

\section{DAFTAR PUSTAKA}

Effendy, Onong Uchjana. 2006, Ilmu Komunikasi: Teori dan Praktek. Bandung: Remaja Rosdakarya

Endraswara, Suwardi. 2003. Metodologi Penelitian Sastra. Yogyakarta: Pustaka Widyatama.

Littlejohn, Stephen W. Karen A.Foss. 2009. TEORI KOMUNIKASI Theories of Human Communication Ed.9. Jakarta: Salemba Humanika

Tinarbuko, Sumbo. 2008. Semiotika Komunikasi Visual, Yogyakarta : Penerbit Jalasutra

Yoseph Andreas Gual, 2012 (Jurnal). Dari Budaya Tinggi - Budaya Rakyat Menuju Budaya Massa - Budaya Populer. UNWIRA KUPANG

36 | Simbol-Simbol Pesan Persuasif Melalui Design Poster Event Musik Ngayogjazz Festival 